\title{
Violência obstétrica: a abordagem da temática na formação de enfermeiros obstétricos
}

\section{Obstetric violence: theme approach in the training of Certified Nurse-Midwives Violencia obstétrica: el enfoque de la temática en la formación de enfermeros obstétricos}

Thalita Monteiro da Silva ${ }^{1}$ iD hittps://orcid.org/0000-0002-6575-5602

Kayo Henrique Jardel Feitosa Sousa² in https://orcid.org/0000-0002-0901-7752

Adélia Dalva da Silva Oliveira ${ }^{1}$ id https://orcid.org/0000-0001-8344-9820

Fernanda Cláudia Miranda Amorim¹ io https://orcid.org//0000-0002-1648-5298 Camila Aparecida Pinheiro Landim Almeida ${ }^{3}$ io https://orcid.org/0000-0003-4843-4572

Silva TM, Sousa KH, Oliveira AD, Amorim

FC, Almeida CA. Violência obstétrica: a abordagem da temática na formação de enfermeiros obstétricos. Acta Paul Enferm. 2020;33:AAPE20190146.

DOI

http://dx.doi.org/10.37689/actaape/2020A001466

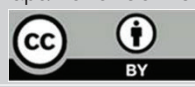

Viôncia: Violência contra a mulher; Mulheres grávidas; Enfermeiras obstétricas; Estudantes de enfermagem; Parto humanizado

Keywords

Violence; Violence against woman; Pregnant women; Nurse midwives; Students, nursing; Humanizing delivery

Descriptores

Violencia Violencia contra la mujer; Mujeres embarazadas; Enfermeras obstetrices; Estudiantes de enfermeira; Parto Humanizado

\section{Submetido \\ 17 de Junho de 2019 \\ Aceito \\ 25 de Março de 2020}

Autor correspondente

Kayo Henrique Jardel Feitosa Sousa E-mail: kayohenriquejardel@hotmail.com

\section{Resumo}

Objetivo: Construir o Discurso do Sujeito Coletivo de Enfermeiros pós-graduandos em Enfermagem Obstétrica sobre a violência obstétrica.

Métodos: Estudo descritivo, de abordagem qualitativa, realizado em um Centro Universitário em TeresinaPI. Participaram 20 Enfermeiros, pós-graduandos em Enfermagem Obstétrica. A coleta de dados ocorreu por meio de entrevistas guiadas a partir de questionário semiestruturado. Os dados foram processados no software IraMuTeQ, utilizando a Classificação Hierárquica Descendente, e analisados pela Técnica do Discurso do Sujeito Coletivo.

Resultados: Mediante a Classificação Hierárquica Descendente, obtiveram-se seis classes das quais emergiram os discursos. Foi possível ratificar a importância da formação do Enfermeiro diante da violência obstétrica. As principais expressões-chave identificadas nos discursos foram: formação acadêmica, conhecimento na prática educativa, assistência de qualidade, descasos científicos, tecnológicos e humanísticos, fortalecimento do modelo assistencial, planejamento estratégico no setor saúde, base humanista e olhar clínico do profissional.

Conclusão: Por meio do Discurso do Sujeito Coletivo, foi possível observar, parcialmente, a importância da formação dos Enfermeiros, visto que possibilitam a contribuição de cuidado integral, corroborando para um processo fisiológico, que pode reduzir a violência obstétrica.

\section{Abstract}

Objective: To construct the Discourse of the Collective Subject of graduate nurses in obstetric nursing on obstetric violence.

Methods: This is a descriptive and qualitative study carried out at a University Center in Teresina, PI. Twenty nurses participated, graduate students in obstetric nursing. Data collection took place through guided interviews using a semi-structured questionnaire. The data were processed using the software IraMuTeQ and the Descending Hierarchical Classification. The data were analyzed using the Discourse of the Collective Subject technique.

Results: Through the Descending Hierarchical Classification, six classes were obtained from which the speeches emerged. It was possible to confirm the importance of training nurses in the face of obstetric violence. The main key expressions identified in the speeches were academic training, knowledge in educational practice, quality assistance, scientific, technological and humanistic mismatches, strengthening of the care model, strategic planning in the health sector, humanist base and professional clinical view. 
Conclusion: Through the Discourse of the Collective Subject, it was possible to partially observe the importance of training nurses, since they enable the contribution of comprehensive care, corroborating a physiological process, which can reduce obstetric violence.

\section{Resumen}

Objetivo: Construir el Discurso del Sujeto Colectivo de enfermeros estudiantes de posgrado en Enfermería Obstétrica sobre la violencia obstétrica.

Métodos: Estudio descriptivo, de enfoque cualitativo, realizado en un Centro Universitario en Teresina, estado de Piauí. Participaron 20 enfermeros estudiantes de posgrado en Enfermería Obstétrica. La recolección de datos se realizó mediante entrevistas guiadas a partir de un cuestionario semiestructurado. Los datos fueron procesados en el software IraMuTeQ, mediante la clasificación jerárquica descendente, y analizados con la técnica del Discurso del Sujeto Colectivo.

Resultados: Mediante la clasificación jerárquica descendente, se obtuvieron seis clases de las cuales surgieron los discursos. Fue posible ratificar la importancia de la formación del enfermero con relación a la violencia obstétrica. Las principales expresiones clave identificadas en los discursos fueron: formación académica, conocimiento en la práctica educativa, atención de calidad, indiferencia científica, tecnológica y humanística, fortalecimiento del modelo asistencial, planificación estratégica en el sector de la salud, base humanista y mirada clínica del profesional.

Conclusión: A través del Discurso del Sujeto Colectivo, fue posible observar, parcialmente, la importancia de la formación de los enfermeros, ya que permiten contribuir con el cuidado integral, corroborando un proceso fisiológico que puede reducir la violencia obstétrica.

\section{Introdução}

A violência obstétrica é considerada um fenômeno socialmente complexo na área da Saúde da Mulher. Sua prevenção requer mudanças em práticas assistenciais durante o ciclo gravídico-puerperal, a fim de reduzir intervenções médicas desnecessárias, que podem ser prejudiciais à saúde física e emocional das mulheres. ${ }^{(1)}$

O tratamento abusivo durante o trabalho de parto e o parto viola os direitos humanos, sendo capaz de influenciar negativamente os desfechos desses processos e desencorajar as mulheres na procura por cuidados futuros. Além disso, é visto como uma violência estrutural que as torna vulneráveis ao sofrimento e à morte. ${ }^{(2)}$

Pesquisa destaca que a violência obstétrica acomete também mulheres que apresentam histórico de aborto. Para a assistência a esse procedimento, o cuidado em saúde deve ser respaldado pela receptividade, informação, orientação e suporte emocional. Contudo, apesar da existência de uma política pública que garante atendimento humanizado à mulher durante o processo de abortamento e que preconiza um atendimento imparcial, a assistência a essa mulher no Sistema Único de Saúde (SUS) não atende às suas necessidades, algumas vezes. ${ }^{(3)}$

Nesse sentido, faz-se importante esclarecer que a relação entre os profissionais de saúde e a parturiente deve ser baseada no cuidado e na segurança, visando uma adequada realização de práticas humanizadas. É necessário que o profissional se coloque no lugar do outro, ouvindo as necessidades da mulher e conhecendo suas demandas no serviço de saúde, reforçando, assim, os princípios preconizado pelo SUS. ${ }^{(4)}$

Reforçam o exposto os resultados encontrados em uma pesquisa que expressaram que as mulheres, em alguns casos, acabam não se adaptando ao ambiente no qual irão "dar à luz" e, muitas vezes, para se livrar do sofrimento e se retirar desse ambiente, concordam com intervençôes desnecessárias, consideradas graves ou prejudiciais à sua saúde física e emocional. Por isso, mudanças nas práticas assistenciais vigentes devem ser realizadas, a fim de reduzir tais intervençôes. ${ }^{(5)}$

Nesse sentido, considera-se que a educação em saúde por meio de açóes educativas pode ser importante para contribuir com a troca de saberes entre os profissionais e as mulheres - no esclarecimento de questionamentos, críticas e na promoção da saúde -, sendo possível repensar as estratégias de atuação frente à temática desse contexto na Atenção Primária à Saúde (APS), ainda durante a assistência pré-natal. ${ }^{(6,7)}$

Assim, o debate sobre essa temática na formação de Enfermeiros se torna de relevância notória no cenário brasileiro, principalmente por destacar a necessidade da abordagem da violência contra a mulher na grade curricular durante a formação acadêmica desses profissionais, seja na graduação, seja na pós-graduaçáo. Desse modo, espera-se que o presente estudo possa contribuir para o fortalecimento da Enfermagem na prática assistencial e para a formação educacional de Enfermeiros, além de suscitar um maior debate dessa prática no cenário Obstétrico. 
Este estudo justifica-se por abordar uma temática atual e relevante, que precisa ser amplamente divulgada e tratada nos diferentes cenários de educação e saúde. Ele apresenta aspectos importantes, como a educação e promoçáo da saúde, o empoderamento feminino e as questóes relacionadas às vantagens econômicas individuais na assistência obstétrica em detrimento do bem-estar maternoinfantil.

O objetivo deste estudo foi construir o Discurso do Sujeito Coletivo de Enfermeiros pós-graduandos em Enfermagem Obstétrica sobre a violência obstétrica.

\section{Métodos}

Estudo descritivo com abordagem qualitativa, desenvolvido em um Centro Universitário de caráter privado, situado na cidade de Teresina-PI. Trata-se de uma Instituição de Ensino Superior (IES), credenciada pelo Ministério da Educação (MEC), que atualmente oferece cursos de graduação e de pós-graduação. Destaca-se o curso de pós-graduação em Enfermagem Obstétrica, que perfaz uma carga horária de 700 horas de disciplinas teóricas e práticas e apresenta como público-alvo Enfermeiros com interesse em aprimorar os conhecimentos na temática.

A amostra foi selecionada por conveniência, incluindo todos os Enfermeiros matriculados regularmente no curso de pós-graduação Latu Sensu em Enfermagem Obstétrica da IES selecionada. Excluíram-se aqueles que se encontravam ausentes no período da coleta de dados, por motivo de afastamento ou licença à saúde.

A população-alvo foi de 40 pós-graduandos em Enfermagem Obstétrica. Contudo, a obtenção de novos discursos cessou com a participação de 20 Enfermeiros, sendo suficiente para atingir a saturação teórica das informaçóes obtidas na coleta dos dados ou seja, quando não houve mais necessidade de novos elementos para balizar ou aprofundar a teorização.

Os participantes foram convidados a participar do estudo na IES durante o intervalo ou no final das aulas, de acordo com o cronograma do curso disponibilizado. A coleta de dados ocorreu entre os meses de agosto e setembro de 2018, e optou-se, para a produção dos dados, pelo uso de entrevista semiestruturada composta pelas seguintes questóes: (1) "Em geral, como pós-graduando em Enfermagem Obstétrica, quais as contribuiçôes da abordagem da temática violência obstétrica durante a formação de Enfermeiros?"; (2) "Fale sobre os aspectos da sua formação acadêmica e qualificação profissional que contribuíram (ou podem contribuir) ou interferiram (ou podem interferir) na atuação profissional no cuidado à mulher durante o ciclo pré-natal-parto-puerpério."; (3) "Na sua opinião, quais seriam as estratégias de superação dos aspectos que interferiram na sua formação acadêmica e qualificação profissional para a sua atuação profissional no cuidado à mulher durante o ciclo pré-natal-parto-puerpério?”.

As entrevistas foram realizadas em hora e local escolhidos pelos participantes, informados previamente sobre o anonimato e o uso de gravador de voz. O tempo médio de duração das entrevistas foi de 15 minutos.

Para o processamento dos dados, organizou-se um corpus textual com as transcrições de todas as entrevistas e utilizou-se o software IRaMuTeQ (acrônimo de Interface de $R$ pour les Analyses Multidimensionnelles de Textes et de Questionnaires) para processamento, a partir da Classificação Hierárquica Descendente (CHD) e dendograma.

Foram identificadas as expressóes-chave (fragmentos dos depoimentos que revelam a essência da argumentação), ideias centrais (síntese, feita pelo pesquisador, que revela o sentido dos depoimentos) e ancoragens (enunciado valorativo, crença ou teoria que é explicitada pelo participante), a partir das quais construiu-se o Discurso do Sujeito Coletivo (DSC), que consiste na forma qualitativa de representar o pensamento de uma coletividade, agregando, em um discurso-síntese, os conteúdos discursivos de sentido semelhante emitidos por pessoas distintas.

O projeto deste estudo foi aprovado pelo Comitê de Ética em Pesquisa (CEP), sob o Parecer n. ${ }^{\circ}$ 2.694.389. Todos os participantes foram informados sobre o anonimato e a natureza voluntária da pesquisa. Do mesmo modo, todos leram, concordaram e assinaram o Termo de Consentimento Livre e Esclarecido, atestando sua anuência para a mesma. 


\section{Resultados}

Dos 20 pós-graduandos em Enfermagem Obstétrica participantes deste estudo, 18 eram do sexo feminino, com média de idade de 24 anos; 17 eram solteiros; e o tempo médio de formação era de 3 anos.

O IRaMuTeQ reconheceu a separação do corpus em 160 Unidades de Contextos Elementares (UCE) e seis classes, tendo aproveitamento de $80 \%$ do total do corpus, valor considerado suficientemente elevado para a análise.

O corpus obteve um eixo, do qual emergiu a classe 6, com 23 UCE (17,97\%), e outras duas subdivisóes: de uma subdivisão emergiu a classe 5 , com 23 UCE (14,06\%), e duas ramificaçôes: a da classe 1 , com 16 UCE (12,5\%), e a da classe 3, com 25 UCE (19,53\%); da outra subdivisão, surgiram a classe 4 , com 30 UCE $(23,44 \%)$, e a classe 2 , com $16 \operatorname{UCE}(12,5 \%)$.
Por meio da CHD, foi possível a interpretação das falas obtidas no corpus da abordagem da temática violência obstétrica na formação de Enfermeiros Obstétricos, nomeadas em seus respectivos sentidos nas seis classes oriundas do dendograma (Figura 1).

As seis classes neste estudo elencaram a abordagem da temática violência obstétrica na formação de Enfermeiros Obstétricos. Conforme pressupostos do DSC, cada Enfermeiro de pós-graduação em Enfermagem Obstétrica entrevistado contribuiu com sua cota de pensamento para o discurso coletivo. Portanto, após a análise da transcrição das entrevistas, a partir das expressóes-chave (E-CH), foram identificadas as ideias centrais (IC), enunciadas conforme a CHD, e construídos os DSC. Em seguida, efetuou-se a normalização dos discursos, a fim de se desparticularizar os depoimentos, dar coerência e coesão às ideias e evitar repetições. $\mathrm{O}$ quadro 1 apresenta as IC, E-CH e discursos-sínteses (DCS).

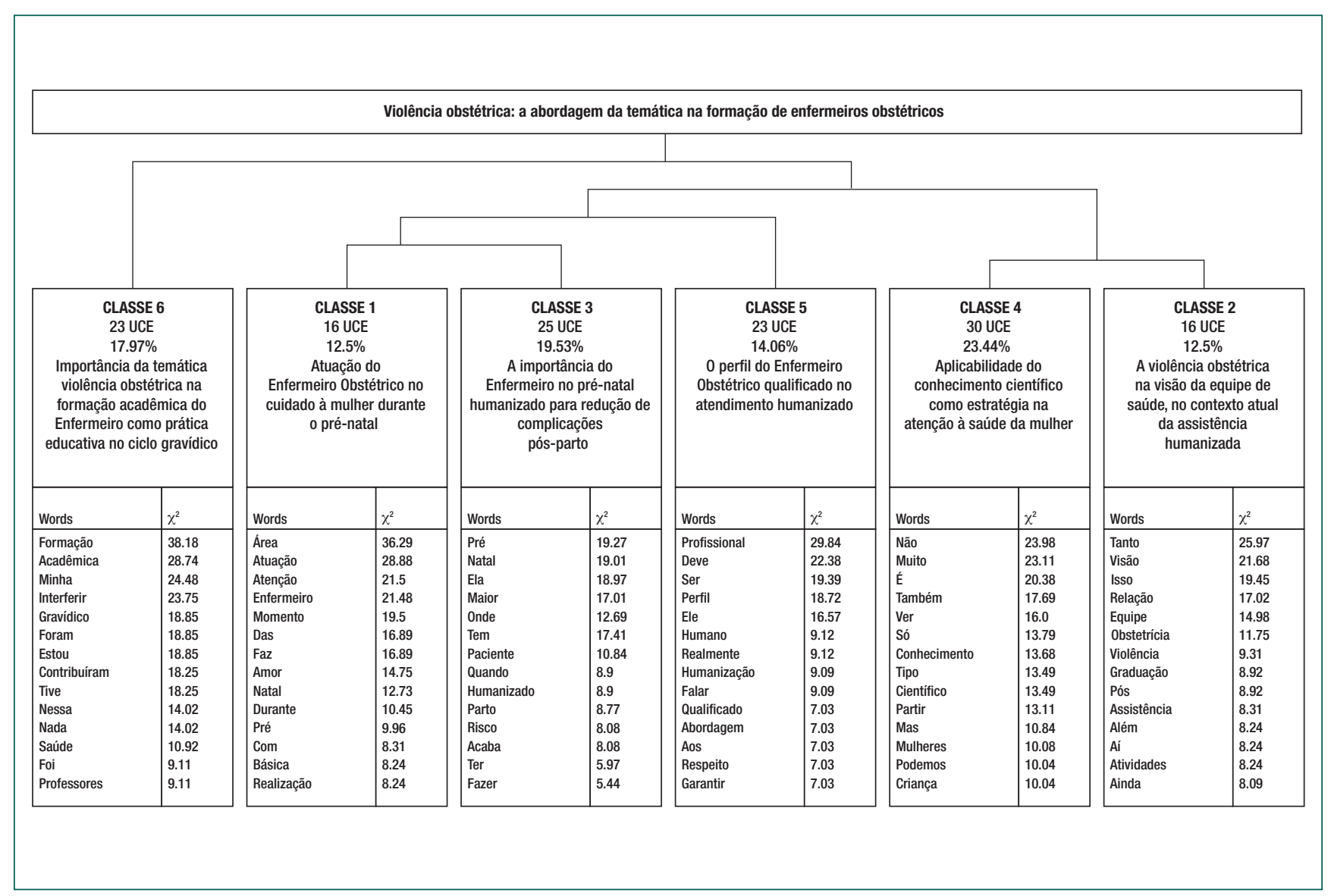

Figura 1. Estrutura temática da abordagem do tema violência obstétrica na formação de Enfermeiros 
Quadro 1. Discursos do sujeito coletivo elaborados por "futuros" Enfermeiros Obstétricos sobre a violência obstétrica

\begin{tabular}{|c|c|c|}
\hline Elementos-chave & Ideias centrais & Discursos do sujeito coletivo \\
\hline $\begin{array}{l}\text { Formação acadêmica. } \\
\text { Conhecimento na prática educativa. } \\
\text { Assistência no ciclo gravídico. } \\
\text { Importância do Enfermeiro. }\end{array}$ & $\begin{array}{l}\text { Importância da temática violência obstétrica } \\
\text { na formação acadêmica do Enfermeiro como } \\
\text { prática educativa no ciclo gravídico. }\end{array}$ & $\begin{array}{l}\text { É de grande valia e importância a temática violência obstétrica, caracterizada pela desumanização do } \\
\text { parto e apropriação indevida dos profissionais da saúde no processo reprodutivo da mulher, na formação } \\
\text { de Enfermeiros. É primordial a assistência no ciclo gravídico como estratégia preventiva no combate } \\
\text { desse fenômeno, a fim de obter uma relação harmônica, minimizando possíveis erros de intercorrências } \\
\text { obstétricas. É ainda crucial o progresso na valorização dos profissionais, o apoio de rede de políticas } \\
\text { públicas, possibilitando uma melhor condição de trabalho no SUS um melhor rendimento financeiro ou } \\
\text { estrutural, com o intuito de despertar um novo olhar científico sobre a prática educativa, desenvolvendo um } \\
\text { pensamento crítico e evitando esse "desvencilhamento". }\end{array}$ \\
\hline $\begin{array}{l}\text { Riscos a partir da falta de cuidado. } \\
\text { Valorização financeira. } \\
\text { Assistência de qualidade. }\end{array}$ & $\begin{array}{l}0 \text { perfil do Enfermeiro Obstétrico qualificado } \\
\text { no atendimento humanizado. }\end{array}$ & $\begin{array}{l}0 \text { termo "provedor qualificado" ressalta exclusivamente o indivíduo com destreza em atenção profissional } \\
\text { do parto, capaz de acompanhar o cuidado da puérpera, desde seu convivio no ambiente familiar até o } \\
\text { seu estado mental. Quando questionado sobre o compromisso assistencial, a maioria dos profissionais e } \\
\text { toda a equipe multiprofissional está dando mais valor ao setor econômico, ou seja, está valorizando mais } \\
\text { a moeda do que a própria humanização. Os profissionais devem priorizar um serviço de qualidade com } \\
\text { conforto, responsabilidade e credibilidade. O perfil de um especialista Obstétrico é de um coadjuvante, e a } \\
\text { protagonista é a própria gestante. Isso significa ter ética profissional, empatia com o próximo e dignidade } \\
\text { humana. }\end{array}$ \\
\hline $\begin{array}{l}\text { Qualidade do cuidado prestado. } \\
\text { Descaso científico, tecnológico e } \\
\text { humanístico. } \\
\text { Direitos à parturiente. }\end{array}$ & $\begin{array}{l}\text { A atuação do Enfermeiro Obstétrico no } \\
\text { cuidado à mulher durante o pré-natal. }\end{array}$ & $\begin{array}{l}0 \text { Enfermeiro Obstétrico visa atender a gestante com qualidade, desejando atingir prioritariamente } \\
\text { parcelas mais pobres da sociedade. Observamos um descaso e até mesmo a ausência da integralidade } \\
\text { ao aprofundar seus aspectos científicos, tecnológicos e humanísticos nesse contexto. É importante para a } \\
\text { gestante receber orientações, conhecendo os procedimentos e seus direitos nesse seguimento parturitivo, } \\
\text { principalmente as mães adolescentes, para que elas estejam preparadas para entrar nesse cenário. }\end{array}$ \\
\hline $\begin{array}{l}\text { Fortalecimento do modelo assistencial. } \\
\text { Riscos no processo parturitivo. }\end{array}$ & $\begin{array}{l}\text { A importância do Enfermeiro no pré-natal } \\
\text { humanizado para a redução de complicações } \\
\text { pós-parto. }\end{array}$ & $\begin{array}{l}0 \text { processo de humanização implica mudanças na rotina, com o propósito de tornar o momento do parto o } \\
\text { menos “medicalizado" possível. Um dos principais objetivos do pré-natal é conhecer o histórico médico do } \\
\text { paciente. É necessário que o Enfermeiro exerça um papel de total fortalecimento no modelo assistencial, } \\
\text { fornecendo uma assistência precoce, pois os riscos evoluem para uma série de problemas que podem } \\
\text { colocar em risco a vida tanto da mãe, quanto do recém-nascido. }\end{array}$ \\
\hline $\begin{array}{l}\text { A importância do conhecimento } \\
\text { cientifico. } \\
0 \text { bem-estar materno e neonatal. } \\
\text { Aprimoramento científico na formação } \\
\text { acadêmica. } \\
\text { Planejamento estratégico no setor de } \\
\text { saúde. }\end{array}$ & $\begin{array}{l}\text { Aplicabilidade do conhecimento científico } \\
\text { como estratégia na atenção de saúde da } \\
\text { mulher. }\end{array}$ & $\begin{array}{l}\text { Ao analisar a violência institucional, percebemos que existe, no que diz respeito a aliar a prática ao } \\
\text { conhecimento cientifico, uma alta complexidade na rede de atenção à saúde da mulher, que serve como } \\
\text { porta de entrada no acolhimento e no bem-estar materno e neonatal. O conhecimento é um instrumento } \\
\text { de informações com foco no processo de aprendizado. A atenção primária é de ampla relevância no } \\
\text { desenvolvimento profissional, visto que compreende uma visão detalhada - ou seja, holística - no } \\
\text { campo de atenção à saúde da mulher, que proporciona condições de promoção de saúde e melhoria no } \\
\text { controle físico e emocional. Diante do alto grau de demanda dos serviços, é necessário um planejamento } \\
\text { estratégico no setor de saúde que vise a elaboração de ações como reestruturação assistencial. }\end{array}$ \\
\hline $\begin{array}{l}\text { Base humanista. } \\
\text { Intervenções no parto. } \\
\text { Olhar clínico do profissional. }\end{array}$ & $\begin{array}{l}\text { A violência obstétrica na visão da equipe } \\
\text { de saúde, no contexto atual da assistência } \\
\text { humanizada. }\end{array}$ & $\begin{array}{l}\text { A humanização seria uma estratégia na produção da saúde, compreendida por uma base humanista, } \\
\text { capaz de transformar a visão do profissional. Para tornar um nascimento satisfatório, é necessário } \\
\text { reduzir intervenções e implantar boas práticas obstétricas terapêuticas, que antes eram pautadas no } \\
\text { entendimento de que o parto estava associado à doença, biologicamente. Hoje, torna-se um modelo de } \\
\text { atenção ampliado, que possibilita o desencorajamento de condutas desnecessárias no trabalho de parto e } \\
\text { parto. O profissional deve ter um olhar clínico para que seja possível analisar e interpretar a violência, a fim } \\
\text { de diminuir esses males que causam tanto sofrimento e acometem a saúde da mulher e do neonato. }\end{array}$ \\
\hline
\end{tabular}

\section{Discussão}

Apesar do contexto desfavorável com relação ao arsenal metodológico às boas práticas, embasadas em evidências científicas, da restrição parcial de Enfermeiros participantes, da não contemplação de pensamentos coletivos e da inserção de pós-graduandos em Enfermagem Obstétrica de outras Instituiçóes e particularmente de outras regióes do Brasil, os dados apresentados não anulam a relevância científica desta investigação, mas apontam a necessidade de qualificação e aperfeiçoamento futuros.

Para a comunidade científica, sugere-se o desenvolvimento de projetos de pesquisas com métodos mais avançados, dada a relevância da temática na formação de Enfermeiros e profissionais de saúde envolvidos na assistência à saúde obstétrica, em benefício de melhores práticas dentro das Unidades
Básicas de Saúde (UBS). Tal prática favorece a implementação de açóes educativas e a minimização de intervençôes obstétricas desnecessárias.

O presente estudo permitiu, a partir do DSC, compreender a importância da temática da violência obstétrica na formação educativa do Enfermeiro no ciclo gravídico, em razão da necessidade de um Enfermeiro Obstétrico qualificado para o atendimento humanizado. Também foi possível evidenciar a importância de haver a reestruturação da assistência ao parto em face à formação acadêmica, tendo em vista que cabe aos profissionais da saúde a criação e utilização de conhecimentos científicos sistematizados e direcionados para a necessidade de cada mulher.

Outro dado observado a partir do DSC diz respeito à prática educativa e à adesão às açóes de promoção à saúde, uma forma de sanar as falhas assistenciais. Para preencher a lacuna existente, é 
necessário um acolhimento que estimule a troca de experiências, gerando vínculo entre paciente e profissional, com o objetivo de minimizar a ansiedade, o medo, a insegurança, as dúvidas e as queixas associadas à gestação.

Dessa forma, são importantes estratégias como o raciocínio crítico e autocrítico e a implementação de grupos terapêuticos que planejem a questão social e política da categoria Enfermeiro Obstétrico, discutindo, assim, a problematização em situação geral. Esse exercício profissional propóe a prática com qualidade das funçóes do profissional de enfermagem. ${ }^{(1)}$

No discurso construído com base nas falas dos profissionais, é possível identificar os riscos provocados pela falta de cuidados humanizados, capaz de ocasionar problemas ao feto durante a gestação. Contudo, ressalta-se que, por vezes, os problemas ocorrem mediados pela equipe de profissionais, que acumula funçóes para agregar lucro, além de enfrentar a alta rotatividade e a precariedade de vínculos empregatícios. Cabe enfatizar ainda que esse fato pode influenciar na humanização - o que ocasiona a negligência profissional - e na incorporação de valores, visto que os profissionais estão mais interessados em questóes socioeconômicas individuais do que em reduzir as taxas de mortalidade maternoinfantil. ${ }^{(8)}$

Esses profissionais são desafiados constantemente na prestação de cuidados. $\mathrm{O}$ sistema de saúde é deficiente por não possuir um padrão de cuidado integral voltado à mobilização pessoal. É de suma importância um mecanismo tecnológico de troca de informaçôes entre os membros da equipe que, quando bem utilizado, possibilite o cuidado contínuo. ${ }^{(9)}$

Com base nisso, ressalta-se também que, para a relação profissional de saúde-paciente, é fundamental que o profissional compartilhe conhecimento com a finalidade de minimizar possíveis equívocos do paciente. Por outro lado, é importante mencionar que ainda existem muitas barreiras a serem enfrentadas, incluindo a ausência da totalidade e da clareza diante das orientaçóes repassadas às gestantes, originando a insegurança da mesma, que interfere diretamente na qualidade de vida e na banalização dos direitos das mulheres. Assim, propóe-se a legitimação de açóes efetivas, com a finalidade de suprimir e prevenir a violência obstétrica. ${ }^{(10)}$
Em concordância com este estudo, pesqui$\mathrm{sa}^{(11)}$ aponta que o diálogo perfaz o direito à parturiente. Nesse contexto, deve ser incentivada pelo Enfermeiro a busca do reconhecimento judicial da mulher pela escolha do parto, além dos direitos de não ser lesionada por manobras desnecessárias, de estar acompanhada por uma pessoa de sua escolha e de ter esclarecimento quanto aos procedimentos.

O reconhecimento judicial é essencial porque as mulheres lesadas nem sempre sabem como procurar reparação, de modo que o diálogo com o Enfermeiro pode permitir medidas de prevenção e informação. ${ }^{(11)}$ Dessa forma, é importante que o Enfermeiro Obstétrico qualificado efetue um atendimento humanizado como forma de melhoria do serviço qualificado e humanístico, ambos capazes de contribuir para uma reflexão positiva.

Este estudo também possibilitou compreender o risco do processo de parturição, que traz um impacto negativo para as gestantes. Considera-se que as intervençóes podem salvar vidas quando adequadamente implementadas, garantindo o total cuidado e fornecendo satisfação materna. ${ }^{(12)}$

O fortalecimento do modelo assistencial é relevante para a formação de profissionais humanizados. Há a necessidade de preparar a parturiente efetivamente e oferecer uma assistência harmônica nesse ciclo gravídico-puerperal, que se resume em técnica, procedimento e embasamento teórico. Vale salientar que a falta de informação gera maiores riscos de complicações no pós-parto para a parturiente. ${ }^{(13)}$

Destaca-se que, para compreender as contribuiçôes do cuidado humanizado, é necessário que os especialistas possuam um papel essencial no cuidado à mulher durante o pré-natal, utilizando práticas clínicas pautadas em evidências, na experiência cuidativa baseada no respeito e apoio emocional. Portanto, torna-se pertinente a identificação de fatores socioculturais, fisiológicos e assistenciais para contribuição no processo de renovação da pesquisa científica. Nesse sentido, justifica-se a reflexão acerca dos profissionais no serviço do pré-natal, pois são os primeiros que precisam ser sensibilizados no âmbito biopsicossocial, garantindo integralidade. ${ }^{(14)}$

Em concordância com este estudo, afirma-se ainda que as complicaçôes maternas ocorrem também 
pelo aumento das cesarianas sem indicação clínica. Pesquisa revelou que as complicações são frequentes e afetam a qualidade de vida das mulheres. Para que sejam feitas as cesarianas é necessário, dessa forma, ter indicaçôes claras, coerentes e prudentes, cujos benefícios superem os potenciais riscos. ${ }^{(15)}$

Foi possível ratificar nos discursos a importância do Enfermeiro no pré-natal, a fim de reduzir o risco de complicações no parto. Dessa maneira, torna-se importante discernir precocemente os problemas que podem surgir e enfrentá-los de maneira correta, de modo a evitar danos irreparáveis. Estudo revelou que a assistência deve ser embasada na promoção e proteção da saúde - e a gestante deve ser protagonista nesse processo -, priorizando todo o contexto assistencial e emocional na prevenção de intercorrências obstétricas. ${ }^{(16)}$

Sobre a quinta ideia central, exposta no Quadro 1, a aplicabilidade do conhecimento científico na temática da violência obstétrica carece de práticas de educação e saúde - ou seja, de saúde prática obrigatória. A inserção dessas práticas favorece a qualidade de cuidados durante as consultas primárias, que visam o acolhimento. Torna-se importante, portanto, que os profissionais priorizem a realização de açóes educativas como forma de melhorar o relacionamento interpessoal no atendimento individual, visando a preparação e a construção de saberes. ${ }^{(17)}$

O conhecimento possibilita proporcionar aos profissionais um espaço de reflexão, visando o princípio da integralidade e o compromisso com a saúde e estendendo essa abordagem à população vulnerável. Essa questão é necessária para a obtenção de leis, punições e formas de denúncia que visem evitar o fator agravante da violência e superar os aspectos emocionais e psíquicos. ${ }^{(18)}$

Diante do exposto, destaca-se a existência de métodos estratégicos capazes de reverter essa situação por meio de diretrizes baseadas em evidências, mudanças de atitudes por parte dos especialistas e fornecimento de cuidados à saúde. Assim, é possível minimizar as agressóes, evitar o desperdício do uso de materiais, incentivar o desenvolvimento de pesquisas sobre novos indicadores e divulgar resultados para a comunidade científica.

Em concordância com o exposto, estudo ${ }^{(19)}$ salientou que a assistência passou por transformaçóes a respeito de seus aspectos éticos, culturais e psíquicos, gerando a autonomia e o empoderamento da mulher, que passa a ser a protagonista no processo parturitivo. Para adotar essa prática, é imprescindível que o profissional proporcione informaçóes consistentes para propagar a diminuição de partos instrumentalizados, uma vez que essa cultura se encontra enraizada na sociedade. $\mathrm{O}$ interesse da intepretação da violência no contexto assistencial atual propóe a segurança e conforto no atendimento do Enfermeiro, o que permite causar benefícios ao binômio mãe-filho.

A realização deste estudo demonstrou a necessidade de refletir sobre a importância do combate à violência obstétrica na formação do Enfermeiro Obstétrico, enfatizando-a, com o objetivo de promover condutas que visam a redução de elevados índices de mortalidade. Dessa forma, acompanhar o trabalho de parto e parto com eficácia e humanização e propagar o acolhimento.

Abordar o tema violência obstétrica na formação do Enfermeiro constitui um papel estruturante na assistência ao parto e é importante para o aprimoramento da qualidade do cuidado às usuárias. Para os futuros especialistas, o ambiente de formação do profissional traz reflexôes e tem a habilidade de conter sistemas desnecessários. $\mathrm{O}$ padrão assistencial torna-se algo desafiador, que deve ser reforçado o tempo todo, não só para profissionais da enfermagem, mas para toda a equipe de saúde. ${ }^{(20)}$

\section{Conclusão}

A formação dos profissionais Enfermeiros na temática da violência obstétrica deve ser mais ampla, pois eles são coadjuvantes dessas experiências, e nelas desempenham importante papel ao oferecer a qualidade de atendimento de saúde que as mulheres necessitam e merecem enquanto cidadãs de direito. Vale ressaltar que, quando a mulher é orientada adequadamente, tem menos chance de sofrer violência obstétrica. Assim, o papel do Enfermeiro em formação é fundamental no que se refere à violência obstétrica, uma vez que esse profissional tem a possibilidade de reduzir os índices desse agravo e 
mudar a realidade social. Foi possível identificar, através dos DSC, que, por meio da existência de políticas de atenção humanizada ao trabalho de parto e parto, como as Diretrizes Nacionais de Assistência ao Parto Normal e a Rede Cegonha, há uma intensificação do aprimoramento científico relacionado à violência obstétrica, repercutindo em melhores práticas na assistência à mulher no processo parturitivo na rede pública de serviços de saúde.

\section{Referências}

1. Carlos GA, Matozinhos FP, Carmo JM, Manzo BF, Duarte ED, Souza $\mathrm{KV}$, et al. Profile of the participants of an advanced course in obstetric nursing. Rev Min Enferm. 2019;23:e-1153.

2. Marrero L, Brüggemann $\mathrm{OM}$. Institutional violence during the parturition process in Brazil: integrative review. Rev Bras Enferm. 2018;71(3):1152-61.

3. Madeiro AP, Rufino AC. Maus-tratos e discriminação na assistência ao aborto provocado: a percepção das mulheres em Teresina, Piauí, Brasil. Cien Saude Colet. 2017;22(8):2771-80.

4. Possati AB, Prates LA, Cremonese L, Scarton J, Alves CN, Ressel LB. Humanization of childbirth: meanings and perceptions of nurses. Esc Anna Nery. 2017;21(4):e20160366.

5. Zanardo GL, Uribe C, Nadal AH, Habigzang LF. Violência obstétrica no Brasil: uma revisão narrativa. Psicol Soc. 2017;29(0):e155043.

6. Camilo BS, Nietsche EA, Salbego C, Cassenote LG, Osto DS, Bock A. Health education actions in primary attention to pregnant and puerperal women: integrative review. Rev Enferm UFPE On Line. 2016;10(Supl.6):4894-901.

7. Quadros JS, Reis TL, Colomé JS. Obstetrical nursing and health education: contributions to the experience of process of parturition. Rev Rene. 2016;17(4):451-8.
8. Warmling CM, Fajardo AP, Meyer DE, Bedos C. Práticas sociais de medicalização \& humanização no cuidado de mulheres na gestação. Cad Saude Publica. 2018;34(4):e00009917.

9. Archibald MM, Barnard A. Futurism in nursing: Technology, robotics and the fundamentals of care. J Clin Nurs. 2018;27(11-12):2473-80.

10. Dias M, Machado VE. Obstetric violence in Brazil: an integrated multiple case study. Humanities \& Social Sciences Reviews. 2018;8(2):117-28.

11. Santos JA, Santos DF, Rennó GM, Bittencourt AC, Alves GE. Perception of the companion in relation their welcoming during childbirth. Rev Enferm UFPE On Line. 2018;12(10):2535-45

12. Çalik KY, Karabulutlu Ö, Yavuz C. First do no harm - interventions during labor and maternal satisfaction: a descriptive cross-sectional study. BMC Pregnancy Childbirth. 2018;18(1):415.

13. Teixeirense MM, Santos SL. From expectation to experience: humanizing childbirth in the Brazilian National Health System. Interface. 2018;22(65):399-410.

14. Balde MD, Bangoura A, Diallo BA, Sall O, Balde H, Niakate AS, et al. A qualitative study of women's and health providers' attitudes and acceptability of mistreatment during childbirth in health facilities in Guinea. Reprod Health. 2017;14(1):4.

15. Mascarello KC, Matijasevich A, Santos ID, Silveira MF. Complicações puerperais precoces e tardias associadas à via de parto em uma coorte no Brasil. Rev Bras Epidemiol. 2018;21(0):e180010.

16. Errico LS, Bicalho PG, Oliveira TC, Martins EF. The work of nurses in high-risk prenatal care from the perspective of basic human needs. Rev Bras Enferm. 2018;71(3 suppl 3):1257-64.

17. Gray T, Mohan S, Lindow S, Farrell T. Obstetric violence: clinical staff perceptions from a video of simulated practice. Eur J Obstet Gynecol Reprod Biol X. 2019;1:100007.

18. Rodrigues DP, Alves VH, Vieira RS, Leão DC, Paula E, Pimentel MM, et al. Obstetric violence in the context of labor and childbirth. Rev Enferm UFPE On Line. 2018;12(1):236-46.

19. Matoso LM. 0 papel do enfermeiro frente à violência obstétrica. C\&D Rev Eletrôn FAINOR. 2018;11(1):49-65.

20. Sousa AM, Souza KV, Rezende ED, Martins EF, Campos D, Lansky S. Practices in childbirth care in maternity with inclusion of obstetric nurses in Belo Horizonte, Minas Gerais. Esc Anna Nery. 2016;20(2):324-31. 